\title{
Test campaign of a ducted wind turbine in real operating conditions
}

\author{
Enrico Valditerra ${ }^{1}$, Massimo Rivarolo ${ }^{2}$ Aristide F. Massardo ${ }^{2}$ and Marco Gualco ${ }^{1}$ \\ ${ }^{1}$ Ghibli Srl, Via Garibaldi 92, 15067 Novi Ligure (AL), Italy \\ ${ }^{2}$ Thermochemical Power Group, DIME, University of Genoa, Via Montallegro 1, 16145 Genoa, Italy
}

\begin{abstract}
Wind turbine installation worldwide has increased at unrested pace, as it represents a $100 \%$ clean energy with zero $\mathrm{CO} 2$ and pollutant emissions. However, visual and acoustic impact of wind turbines is still a drawback, in particular in urban areas. This paper focuses on the performance evaluation of an innovative horizontal axis ducted wind turbine, installed in the harbour of Genova (Italy) in 2018: the turbine was designed in order to minimize visual and acoustic impacts and maximize electrical energy production, also during low wind speed periods. The preliminary study and experimental analyses, performed by the authors in a previous study, showed promising results in terms of energy production, compared to a traditional generator ( factor $>2.5$ on power output). In the present paper, the test campaign on a scaled-up prototype, installed in the urban area of Genova, is performed, with a twofold objective: (i) comparison of the ducted innovative turbine with a standard one, in order to verify the increase in energy production; (ii) analysis of the innovative turbine for different wind speeds and directions, evaluating the influence of ambient conditions on performance. Finally, based on the obtained results, an improved setup is proposed for the ducted wind turbine, in order to further increase energy production mitigating its visual impact.
\end{abstract}

\section{Introduction}

European Union (EU) recently set several energy policy targets, already defined for 2020 and 2030 Time Horizons. In 2008, EU approved a first package of Directives, aimed to higher diffusion of Renewable Energy Sources (RES), promotion of energy efficiency and cut of $\mathrm{CO}_{2}$ emissions in order to mitigate GHGs impact. More recently, in 2018, EU has published new directives aimed at a further step of energy targets for 2030 [1].

Because of the above-mentioned energy policies, EU countries experimented a significant RES production increase from 947.7 TWh in 2007 up to $2636.5 \mathrm{TWh}$ in 2016. Wind energy has shown a very significant growth, from 105.6 TWh in 2007 up to 320.5 $\mathrm{TWh}$ in 2016, with an actual installation capacity of about $162 \mathrm{GW}$ [2]. In Italy, the installed wind power capacity has constantly increased in the last fifteen years, up to the present value of $9.8 \mathrm{GW}$ [2][3]; similarly, the production has increased up to $17.7 \mathrm{TWh}$. It is worth noting that, in the last three years, despite the installed capacity has increased slightly (+356 MW in 2017), a large number of small plants has been installed (the number increased by $61 \%$ only in the last year, with more than 2,000 new facilities) [2]. 
The installation of large wind turbines is limited by several factors, such as the significant acoustic and visual impact, the danger that they represent for volatile fauna and, above all, the access to remote areas, where the electrical connection can add significant cost burden to the investment. On the other hand, the turbine size is a limiting constrain in terms of rotor diameter in small scale power plants [4-6]; the available power decreases due to the reduced, and sometimes insufficient, wind velocity.

Increasing the power generated by the turbine maintaining the same rotor dimension can be a worthy solution to solve the above reported issues. A promising solution involves the use of systems where the rotor is inserted in the throat section of a generally convergentdivergent duct: the duct shape accelerates the wind speed at the machine section. Such systems are known in literature as shrouded, ducted or lens wind turbines [7-9].

In previous research work [10, the authors analyzed the design of a ducted wind turbine to be installed in the throat section of a convergent-divergent duct. The prototype was built and then tested in the wind tunnel at University of Genoa, with the final aim to maximize the produced power. In the present work, the monitoring data of the ducted turbine, installed in 2018 in the industrial harbour of Genoa, are presented and analyzed for the first time.

\section{Ducted wind turbine geometry}

The proposed solution, investigated and tested in the University of Genoa (UNIGE) wind tunnel in a previous research work [10], has a convergent-divergent geometry; the rotor of the turbine is installed at the throat section, where the velocity is the highest. The lab-scale prototype is shown in Figure 1. The optimization of the geometry led to the definition of the following parameters:

- Ratio between rotor diameter and inlet diameter equal to 0.5 ;

- Ratio between convergent and divergent lengths equal to 0.2 ;

- Same dimension of inlet and outlet diameters.
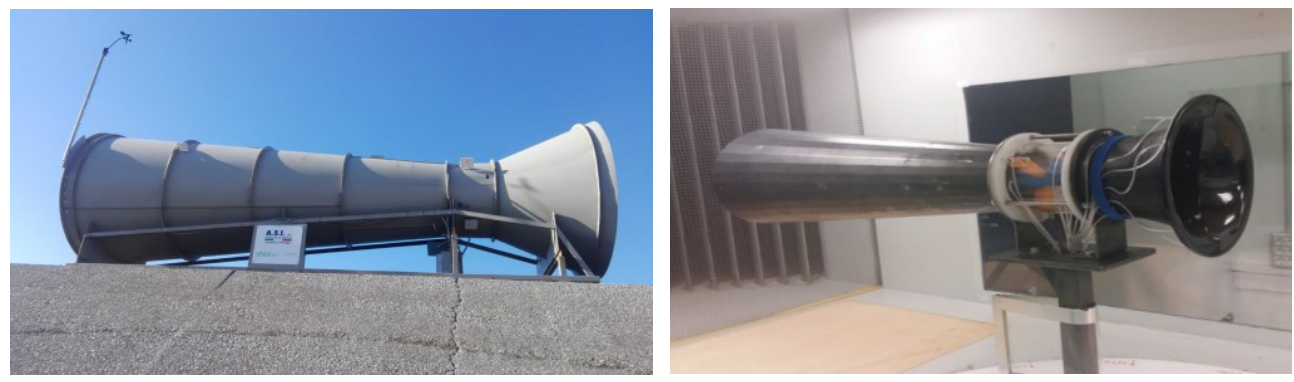

Fig. 1. Prototype of the wind ducted turbine installed in the harbour (left) and laboratory scale (right)

With the above reported geometry, considering a total length of $1 \mathrm{~m}$ for the laboratory model, the Authors found a Wind Velocity Gain (WVG) higher than 1.3 in terms of ratio between inlet velocity and velocity at the throat section, where the rotor is placed. In terms of power, an increase of a factor of 2.55 has been measured, compared with a free turbine (without the convergent-divergent duct). From the tests carried out at UNIGE wind tunnel an increase, in terms of velocity, was found in case of non-axial wind directions, with angles from $0^{\circ}$ (axial direction) up to $\pm 45^{\circ}$; maximum values in terms of power were found for yaw angles of about $\pm 30^{\circ}$. This interesting result was not reported in the open literature to date. 
Starting from the geometry optimization performed by UNIGE, a larger scale prototype has been designed: the new device has a diameter of $1 \mathrm{~m}$ at the throat section, an inlet diameter of $2 \mathrm{~m}$ and a total length of about $6.5 \mathrm{~m}$ ( $1 \mathrm{~m}$ for the convergent part, $5 \mathrm{~m}$ for the divergent and the remaining part for the rotor placing).

The prototype was installed in the urban area of Genova, more precisely in the harbour of Genova Voltri. The machine was oriented along the North-South direction. The monitoring analysis performed in the new installation area has different aims, including:

1. To verify the increase of performance of the ducted turbine, observed in UNIGE wind tunnel

2. To perform a test campaign to assess the intensity and the frequency of the wind for the proposed installation area

3. To verify the increase of production at different yaw angles in real operating conditions

\section{Test campaign}

\subsection{Comparison of free vs ducted turbine}

As stated above, the first aim of the wind test campaign is the comparison of the performance between a traditional configuration (free turbine) and the innovative one (ducted turbine). In order to evaluate this aspect, two equal turbines have been placed to operate simultaneously in parallel. The results, reported for two representative days, confirm the trend suggested by the wind tunnel experimental tests: the higher production of the ducted wind turbine is evident, about three times higher, as Figure 2 shows.

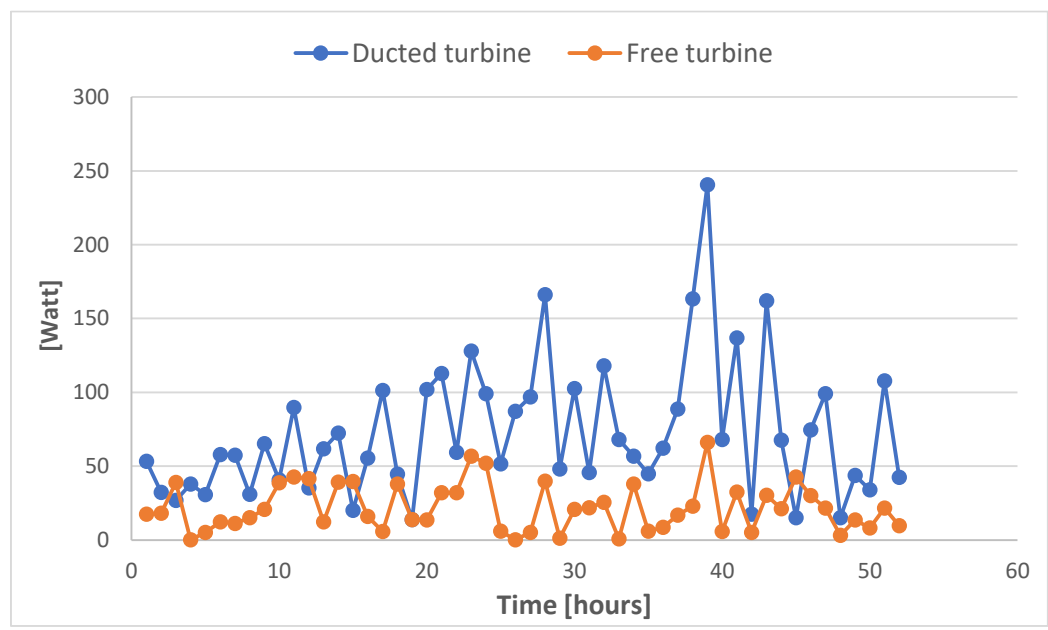

Fig. 2. Comparison between ducted and traditional "free" wind turbines on a representative day

Figure 2 also shows that, in some periods characterized by low wind velocity, the ducted turbine can produce electrical energy when the "free" turbine is off: in fact, the ducted turbine, thanks to its configuration, receives an inlet wind that is about 1.3 times higher, leading to important advantages for its practical use. 


\subsection{Wind test campaign}

After the preliminary comparative analysis, necessary to confirm the higher potential in production of the ducted device, a wind campaign started (December 2018) in order to evaluate both the intensity and the wind direction over time for the specific site of the test rig: this last aspect represents a key parameter, as explained in Figure 3. The test rig analysis showed that, for winds in axial direction entering correctly the ducted section, the production increase should be about 2.5 times (with a WVG of about 1.3). For wind directions comprised in the $\pm 30^{\circ}$ range the production should further increase, up to 3 times; for wind directions comprised between $\pm 30^{\circ}$ and $\pm 60^{\circ}$, the power gain would slighty reduce again in the interval 2.5 to 3 times; other wind directions are not acceptable, since the wind could not enter correctly in the convergent-divergent duct where the rotor is placed, and the power production would become not possible. In such cases, power production could be possible only by rotating the whole frame of the ducted turbine, which was not possible in the test rig.
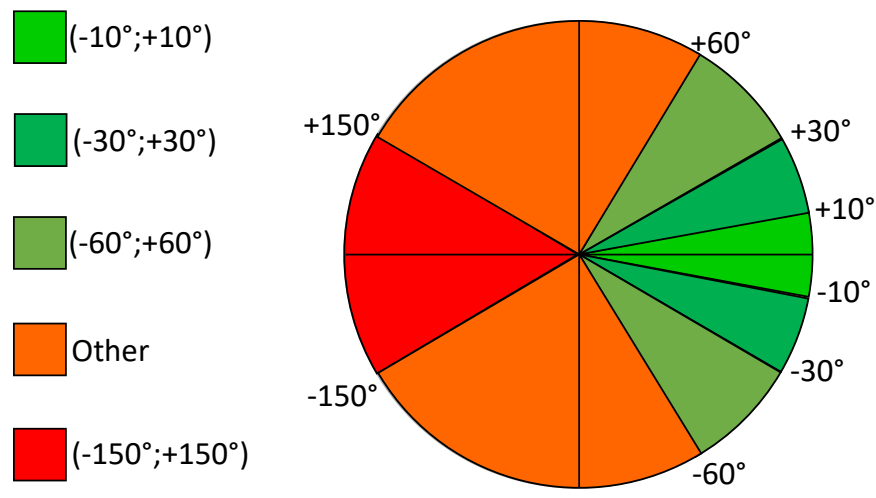

AXIAL DIRECTION

Fig. 3. Possible wind directions

Figure 4 shows the frequency of different wind directions in the installation site: although the analysis is still ongoing, for the first four operating months some interesting aspects can be observed.

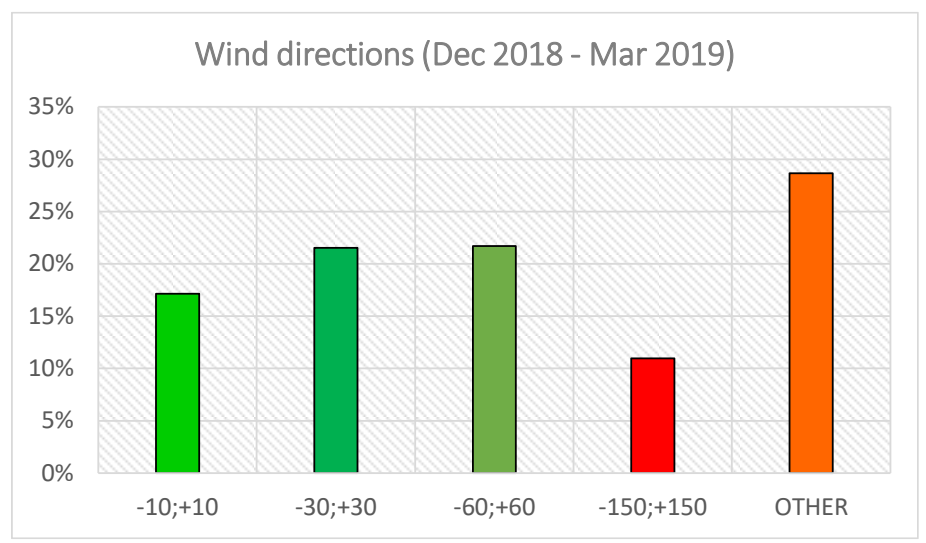

Fig. 4. Wind direction frequency in 4 months (December 2018 - March 2019) 
The distribution of the directions includes about $60 \%$ of the directions that are feasible with the orientation of the device (green column), while for $10 \%$ of the periods the wind enters in the opposite direction and for the remaining $30 \%$ the wind is perpendicular to the axis of the device, therefore the machine would stop. Another interesting aspect is represented by wind intensity: the final analysis will be performed on one entire year of campaign, but some conclusions can be drawn observing the first four months, as reported in Figure 5. There are a significant number of periods (52\% in February, $47 \%$ in December, $42 \%$ in January and 33\% in March) where the wind velocity is lower than $2 \mathrm{~m} / \mathrm{s}$. Velocities higher than $7 \mathrm{~m} / \mathrm{s}$ are very rare: they occur less than $10 \%$ of the time, in all the monitored months. March seems to be the most favourable month, while February is the worst, with more than $30 \%$ of the time without wind.
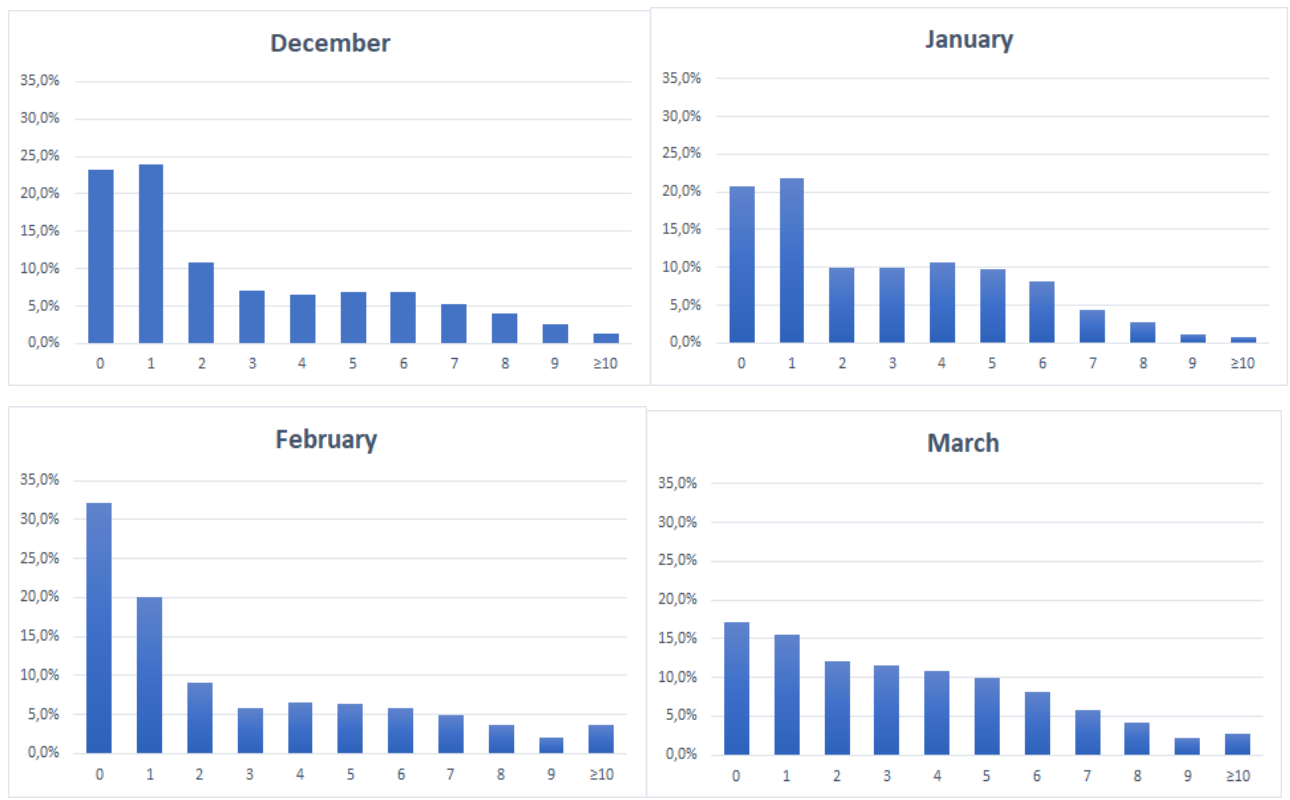

Fig. 5. Wind intensity frequency in 4 months (December 2018 - March 2019)

Figure 6 shows wind and power distribution over time, considering one operational week in March. The maximum produced power is about $280 \mathrm{~W}$. In the last three days, wind velocity is very low $(0-2 \mathrm{~m} / \mathrm{s})$ and production is zero for the most of the time. 


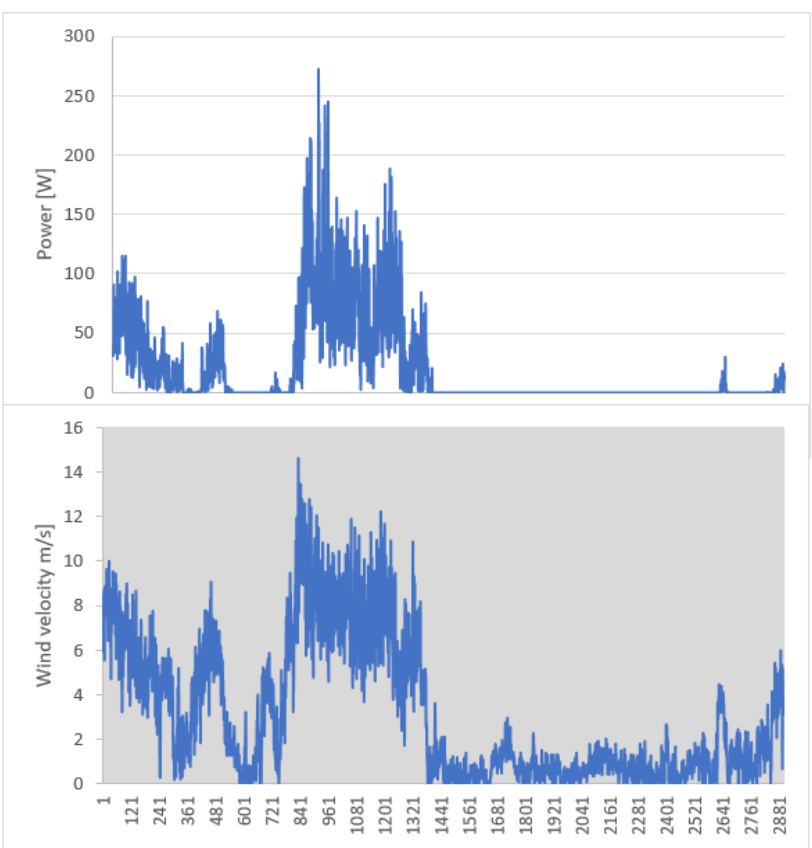

Fig. 6. Wind velocity and corresponding production $\left(24^{\text {th }}-31^{\text {st }}\right.$ March 2019)

\section{Conclusions}

The present paper has investigated an innovative ducted wind turbine, with a convergentdivergent shape and the rotor installed in the throat section. The turbine, previously designed and investigated at University of Genoa wind tunnel, has been scaled up and then installed in the urban area of the industrial harbour of Genoa.

In the first part of the campaign, the ducted turbine has been compared with a traditional one, confirming the increase of produced power (up to three times higher), already observed in the wind tunnel.

At the same time, the monitoring of wind direction and intensity has shown that the installation site could not represent the best solution, for two different reasons:

-High number of periods with very low velocities $(0-2 \mathrm{~m} / \mathrm{s}$ for about $43 \%$ of the time, on four months basis);

-Absence of a main wind direction: this fact may represent a problem for a ducted turbine, since the wind should enter the turbine on the turbine axis, with a maximum yaw angle of $\pm 60^{\circ}$.

As a consequence, since in several periods the wind was very low, the data collected are not sufficient to establish the correlation between wind direction and power production increase.

Despite the above reported negative aspects, the monitoring activity is ongoing in order to collect more data and to verify, on a more significant period (i.e. one year), the influence of wind direction on performance. It is worth noting that, since the device can be easily transported, the possibility of a different site with higher wind availability is under evaluation.

\section{References}


1. https:/ec.europa.eu/energy/en/topics/energy-strategy-and-energy-union/2030-energystrategy access 31/01/2019

2. Elaborations of historical data available from Italian transmission system operator Terna, https://www.terna.it/it-it/sistemaelettrico/statisticheeprevisioni/datistatistici.aspx last access 31/1/2019.

3. www.iea.org last access 31/01/2019.

4. Scappatici L., Bartolini N., Castellani F., Astolfi D., Garinei A., Pennicchi M., Journal of Wind Engineering and Industrial Aerodynamics, 154 (2016), 58-68.

5. Karthikeyan N., Murugavel K.K., Kumar S.A., Rajakumar S., Renewable and Sustainable Energy Reviews, 42 (2015), 801-822.

6. Bukala J., Damaziak K., Kroszcynski K., Krzeszowiec M., Malachowski J., Journal of Wind Engineering and Industrial Aerodynamics, 146 (2015), 29-38.

7. Franković, B., \& Vrsalović, I., Renewable Energy, 24 (2001), 491-499.

8. Bet, F., \& Grassmann, H., Renewable Energy, 28(2003), 71-78.

9. Wang, S.-H., \& Chen, S.-H., Journal of Mechanical Science and Technology, 22(2008), 1984-1992.

10. Rivarolo M., Spoladore A., Cravero C., Traverso A., Freda A., Torrielli S. et al., Proceedings of the ASME Turbo Expo 2018, Lillestrøm (Oslo), Norway. 